\title{
Vitamin $A_{1}$ Aldehyde in the Eggs of the Herring (Clupea harengus $L_{\text {.) }}$ and other Marine Teleosts
}

\author{
BY P. A. PLACK, S. K. KON AND S. Y. THOMPSON \\ Unit for Biochemical Research Bearing on Fisheries' Problems* at the National Institute \\ for Research in Dairying, University of Reading
}

(Received 7 August 1958)

In the course of a study of vitamin $A$ in herring, vitamin $\mathbf{A}$ ester and alcohol and carotenoids were estimated by our usual method (Thompson, Ganguly \& Kon, 1949; Fisher, Kon \& Thompson, $1952)$ in the ovaries of herring of various ages and maturities. This method involves extraction with light petroleum in the presence of ethanol, chromatography, saponification and measurement of vitamin $\mathbf{A}$ by the Carr-Price test. Only small amounts of vitamin A were found, of the order of $0 \cdot 1 \mu \mathrm{g} . / \mathrm{g}$., together with about $1.0 \mu \mathrm{g} . / \mathrm{g}$. of carotenoids, mostly xanthophylls. Scheunert \& Schieblich (1934), using a rat-growth method and the cure of xerophthalmia, showed that the gonads of female herring contain substantial amounts of vitamin A, and Junker (1952-53), with the vaginalsmear assay, found 1-11 $\mu \mathrm{g}$. of vitamin $\mathrm{A} / \mathrm{g}$. of herring ovary, depending on the maturity of the fish. The higher concentrations were in herring about to spawn or spawning. Junker (1956) has also shown that the hard roes of many other fishes contain substantial amounts of vitamin A detectable by biological assay.

We therefore carried out biological and chemical assays of the vitamin A activity of further samples from ripe and running fish of herring hard roe, which consists essentially of unfertilized eggs, and found that the biological activity, determined by the chick liver-storage method, was some ten times that chemically determined. This paper deals with the investigation of the discrepancy, which proved to be due to the presence in the eggs of vitamin $A_{1}$ aldehyde, not estimated in our routine chemical method. Two preliminary reports have already been published (Fisher, Harrison, Kon, Plack, Thompson \& Todd, 1956a; Plack, Thompson \& Kon, 1957).

\section{EXPERIMENTAL}

\section{Materials}

Herring eggs. Quick-frozen herring were purchased from a Reading fishmonger. The fish were caught off East Anglia in the autumn fishery and were mostly ripe and running. They were thawed by immersing in warm water

\footnotetext{
* Grant-aided by the Development Fund.
}

and sexed by squeezing the fish and observing whether eggs or milt were extruded. The males and immature females were discarded and the roe was removed from the remaining females through a ventral cut. Care was taken to exclude portions of the intestine or other organs. Except for batch C, the roes were blended in an Ato-Mix blender (Measuring and Scientific Equipment Ltd.) in an atmosphere of nitrogen and each batch was thoroughly mixed before storage at $-20^{\circ}$ in polythene bottles or bags. With batch $\mathcal{C}$, each roe was cut into 16 pieces of about equal size and distributed amongst 16 polythene bottles, the contents of each being mixed by blending before use. The following table shows the dates of purchase of the different batches and the year of catch:

$\begin{array}{ccc}\text { Batch } & \text { Date of purchase } & \text { Date of catch } \\ \text { A } & \text { 10 Feb. } 1956 & \text { Oct.-Nov. 1955 } \\ \text { B } & \text { 15 Jan. 1957 } & \text { Oct.-Nov. 1956 } \\ \text { C } & \text { 1 Apr. 1957 } & \text { Oct.-Nov. 1956 } \\ \text { D } & \text { 17 June 1957 } & \text { Oct.-Nov. 1956 } \\ \text { E } & 10 \text { Apr. 1958 } & \text { Oct.-Nov. 1957 }\end{array}$

Batches B-D were therefore essentially the same raw material but had slightly different storage conditions.

Other fish eggs. Dr B. B. Rae (Scottish Home Department, Marine Laboratory, Aberdeen) supplied the other fish eggs used in this work. They were stored in deepfreeze until used.

Chemicals. Light petroleum, b.p. 40-60,$n$-hexane, acetone, $\mathrm{CHCl}_{3}$ and diethyl ether (anaesthetic ether) were used as supplied by May and Baker Ltd. Aluminium oxide, for chromatographic-adsorption analysis (B.D.H. Alumina) was obtained from British Drug Houses Ltd., activated alumina, type $O$ (P.S. Alumina) from Peter Spence and Sons Ltd., Widnes, and crystalline vitamin $A_{1}$ alcohol from Roche Products Ltd. Other chemicals were of A.R. quality or the purest available commercially.

\section{Methods}

Preparation of homogenates. Portions of $5 \mathrm{~g}$. of herring eggs were homogenized for $2 \mathrm{~min}$. with $7 \cdot 5 \mathrm{ml}$. of ice-cold $0.9 \% \mathrm{NaCl}$ soln. in a glass Potter-Elvehjem homogenizer previously cooled to $0^{\circ}$. For feeding, the supernatant liquid and the solid residue were separated by centrifuging for $45 \mathrm{~min}$. at $20000 \mathrm{~g}$. For chemical work, the homogenate was diluted to $30 \mathrm{ml}$. with water and the supernatant liquid separated by centrifuging at $1400 \mathrm{~g}$.

Dry-matter content. Samples from each batch of herring eggs were dried in stainless-steel dishes in an electric oven at $100^{\circ}$ to constant weight, and the percentage of dry matter was determined. 
Extraction of eggs. Portions of $60 \mathrm{~g}$. of eggs were blended in an Ato-Mix blender with $200 \mathrm{ml}$. of light petroleum for 2 min. in a nitrogen atmosphere. Ethanol, $76 \mathrm{ml}$., was then added rapidly and the whole blended for another 2 min. The mixture separated well into two layers as soon as blending ceased, and the top light-petroleum layer was decanted directly into a brown 11 . conical flask. Two further extractions with $200 \mathrm{ml}$. of light petroleum only were carried out and the three extracts combined. The combined extracts were allowed to stand for $1 \mathrm{hr}$. or longer for the suspended matter to settle, and the clear supernatant liquid was evaporated in a tared flask on a steambath. The last portions of solvent were removed under reduced pressure with little or no heating. After weighing, the extracted lipid was dissolved in $n$-hexane and the total volume made to $16 \mathrm{ml} . / 60 \mathrm{~g}$. of eggs.

Two alternative ways of extracting herring eggs with $\mathrm{CHCl}_{3}$-methanol mixtures were tried. (i) In the first, $50 \mathrm{~g}$. of eggs was blended with $300 \mathrm{ml}$. of $\mathrm{CHCl}_{3}-$ methanol $(1: 1, v / v)$. The extract was separated by centrifuging, and the residue extracted in the same way with three lots of $200 \mathrm{ml}$. of the solvent mixture. The combined extracts were evaporated under reduced pressure and the residue was extracted twice with $\boldsymbol{n}$-hexane. This solution was evaporated and the lipids. were weighed and made to a known volume with $n$-hexane. (ii) In the second method, freezedried eggs equivalent to $60 \mathrm{~g}$. wet wt. were refluxed for 30 min. periods with three $300 \mathrm{ml}$. portions of $\mathrm{CHCl}_{3}-$ methanol $(2: 1, v / v)$. As before, the extracts were separated by centrifuging and the lipids soluble in $n$-hexane were isolated.

Acetone treatment. Again two methods were used. (i) In the first, herring-egg lipid extract $(24 \mathrm{ml}$.) equivalent to $90 \mathrm{~g}$. of eggs was taken to dryness and the residue dispersed in $20 \mathrm{ml}$. of acetone at room temperature. The acetone-soluble and acetone-insoluble parts were separated by centrifuging for $10 \mathrm{~min}$. at $1200 \mathrm{~g}$ and the latter extracted with two further $20 \mathrm{ml}$. portions of acetone. The solvent was removed from the combined acetone extracts and the residue made to $24 \mathrm{ml}$. with light petroleum. The acetone-insoluble fraction was similarly made to $24 \mathrm{ml}$. (ii) In the second method, the solvent was removed from a suitable volume of herring-egg extract and the residue was dispersed in the same volume of acetone and left for $1 \mathrm{hr}$. at room temperature in the dark. The acetone was then removed completely by evaporation and the residue taken up in the original volume of $n$-hexane.

Saponification. The method described by Plack (1956) was used except that the aq. KOH soln. was $60 \%$ (w/w).

Chromatography. Carotenoids and the different forms of vitamin $A_{1}$ were separated on alumina by the following chromatographic methods. (a) Ethanol-weakened B.D.H. Alumina. The method of Thompson et al. (1949) was used with the modification described by Kon, McGillivray \& Thompson (1955). Elution with about $40 \mathrm{ml}$. of $2 \%(\mathrm{v} / \mathrm{v})$ acetone in $n$-hexane removed carotenes, vitamin $A_{1}$ ester and vitamin $A_{1}$ aldehyde. Free xanthophylls and vitamin $A_{1}$ alcohol were then eluted with about $40 \mathrm{ml}$. of $8 \%(v / v)$ ethanol in $n$-hexane. (b) Ethanol-weakened heated B.D.H. Alumina. B.D.H. Alumina was first dried by heating to $150-160^{\circ}$ overnight in a ventilated electric oven. The procedure was then as described above. (c) Water-weakened P.S. Alumina. P.S. Alumina was heated to $150-160^{\circ}$ overnight. The alumina was covered with light petroleum, and water equal to $10 \%$ of the weight of alumina was added dropwise with shaking (Ball, Goodwin \& Morton, 1948). A column $20 \mathrm{~cm}$. long and $1.8 \mathrm{~cm}$. diam. was made up from the slurry, the extract put on in light petroleum and the eluates from successive $150 \mathrm{ml}$. lots of light petroleum, $5 \%(v / v)$ and $10 \%(v / v)$ diethyl ether in light petroleum and pure diethyl ether were collected. (d) Gradient elution from water-weakened P.S. Alumina. For the quantitative separation of vitamin $A_{1}$ ester and aldehyde, a gradientelution technique was used. A $500 \mathrm{ml}$. Pyrex reagent bottle was filled to the top with light petroleum $(550 \mathrm{ml}$.) and placed on a magnetic stirrer. A $1 \mathrm{~mm}$. bore capillary tube fed into the middle of the bottle from a $250 \mathrm{ml}$. separating funnel containing $250 \mathrm{ml}$. of diethyl etherlight petroleum $(1: 1, v / v)$. The outlet was from the bottom of the bottle up through the neck and by a U-shaped capillary to the chromatography tube. At the necks of the bottle and the tube, the capillaries passed through rubber bungs which were not in contact with the solvents. The tube was $30 \mathrm{~cm}$. long by $1 \mathrm{~cm}$. diam. with a sintered-glass base and a tap outlet below it (Quickfit and Quartz Ltd.). It was fitted with a tube, $45^{\circ}$ to the vertical, between the sintered glass and the tap. This tube was normally closed but could be unstoppered to release the liquid accumulated above the tap. A column, $20 \mathrm{~cm}$. long, of water-weakened alumina was prepared, the chromatography tube being tapped to pack the column. The upper part of the tube was washed free from alumina with light petroleum, and a layer of anhydrous $\mathrm{Na}_{2} \mathrm{SO}_{4}$ put on to the column through the light petroleum above it. The extract was added in light petroleum or in $n$-hexane and was washed into the column with three $1 \mathrm{ml}$. lots of light petroleum. Before the column became dry, it was attached to the outlet tube from the mixing bottle and elution begun. The head of liquid above the top of the column was $80-70 \mathrm{~cm}$. and the rate of flow about $1 \mathrm{ml} . / 20 \mathrm{sec}$. Thirty fractions of $8 \mathrm{ml}$. were collected in graduated test tubes, and Fig. 1 shows the concentrations of diethyl ether associated with each. The extinctions of each fraction at 325 and $370 \mathrm{~m} \mu$ were read directly in a Beckman model DU quartz spectrophotometer against light petroleum. Fractions showing greater absorption at $370 \mathrm{~m} \mu$ than at $325 \mathrm{~m} \mu$ (see Fig. 1) were assumed to contain vitamin $A_{1}$ aldehyde and were combined

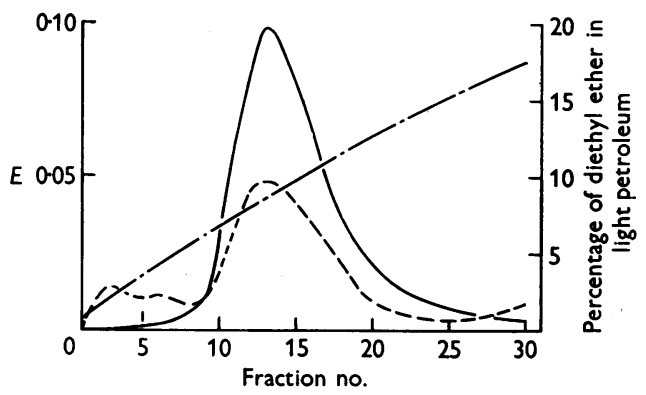

Fig. 1. Separation of vitamin $A_{1}$ aldehyde from a lightpetroleum extract of herring eggs by gradient elution from water-weakened P.S. Alumina. - Extinction of the fractions at $370 \mathrm{~m} \mu ;-.$. , extinction of the fractions at $325 \mathrm{~m} \mu ;-\cdot-\cdot$, concentration of eluent $[\%(v / v)$ of diethyl ether in light petroleum] at the end of each fraction. 
and evaporated to dryness. The residue was weighed and dissolved in $\mathrm{CHCl}_{3}$ for the estimation of aldehyde by the Carr-Price test. Allowance was made for the volume of the residue, a density of $0.9 \mathrm{~g} . / \mathrm{ml}$. being assumed.

Estimation of carotenoids. Carotenoids were estimated in $\mathrm{CHCl}_{3}$ solution, after saponification and chromatography, as described by Thompson (1949).

Carr-Price reaction. All chemical estimations of vitamin A were made by the Carr-Price test. The spectrophotometer and method of Thompson (1949) were used to measure the intensity of the blue colours produced by vitamin $A_{1}$ alcohol and by vitamin $A_{1}$ aldehyde at their respective maxima, 620 and $664 \mathrm{~m} \mu$. One drop of acetic anhydride was always used. Esters of vitamin $A_{1}$ were saponified to the alcohol form before estimation. For vitamin $A_{1}$ alcohol, the colour produced corresponds to $E_{1}^{1 \%}(620 \mathrm{~m} \mu)=5000$ (Fisher, Kon \& Thompson, 1956b). This factor was used in the calculation of vitamin $A_{1}$ concentration. Values for vitamin $A_{1}$ ester are given in terms of the equivalent weight of vitamin $A_{1}$ alcohol. With vitamin $A_{1}$ aldehyde, the colour increases in intensity until a maximum is reached $1.5-2.0 \mathrm{~min}$. after addition of the antimony trichloride solution. The spectrophotometer reading at this maximum is almost twice the initial reading and corresponds to $E_{1}^{1 \%} \mathrm{~cm}$. $(664 \mathrm{~m} \mu)=3820$, as determined with crystalline all-trans vitamin $\mathbf{A}_{1}$ aldehyde prepared as described below. This factor was used to calculate the concentration of vitamin $A_{1}$ aldehyde. At wavelengths greater than $664 \mathrm{~m} \mu$ the Beckman quartz spectrophotometer was used to measure the intensity of the blue colour in the Carr-Price test.

Measurement of absorption. The Beckman spectrophotometer was used to determine absorption curves in the ultraviolet and in the visible regions of the spectrum in matched quartz cells of $1 \mathrm{~cm}$. light path.

Preparation of all-trans vitamin $A_{1}$ aldehyde. A solution of $1 \mathrm{~g}$. of crystalline all-trans vitamin $A_{1}$ alcohol in $98 \mathrm{ml}$. of light petroleum with $2 \mathrm{ml}$. of ethanol was prepared and passed through a $1 \mathrm{~cm} . \times 1 \cdot 2 \mathrm{~cm}$. column of precipitated manganese dioxide (Attenburrow et al. 1952) in $45 \mathrm{~min}$. The column was washed with a small volume of $8 \%$ ethanol in $n$-hexane. Solvent was removed from the combined eluate and a small volume of $n$-hexane added to the residue. This solution was chromatographed on a $20 \mathrm{~cm} . \times 1.8 \mathrm{~cm}$. column of ethanol-weakened B.D.H. Alumina and the $2 \%$ acetone in $n$-hexane and $8 \%$ ethanol in $n$-hexane eluates were collected. The latter contained unchanged vitamin $\mathbf{A}_{1}$ alcohol and was again put through the oxidation and chromatography steps. After combination of the $2 \%$ acetone in $n$-hexane eluates and removal of the solvent, the aldehyde residue weighed $0.80 \mathrm{~g}$. It was dissolved in $14 \mathrm{ml}$. of light petroleum and crystallized at $-20^{\circ}$; yield $0 \cdot 37 \mathrm{~g}$. Recrystallization from $7 \cdot 4 \mathrm{ml}$. of light petroleum yielded $0.28 \mathrm{~g}$. of all-trans vitamin $A_{1}$ aldehyde.

A similar preparation gave $E_{1}^{1} \%=1450$ at $\lambda_{\max .} 381 \mathrm{~m} \mu$ in ethanol [Robeson, Blum, Dieterle, Cawley \& Baxter (1955) give $E_{1}^{1 \%}=1530$ at $\lambda_{\max } .381 \mathrm{~m} \mu$; Hubbard, Gregerman \& Wald $(1952-53) \quad E_{1}^{1} \%=1600$ at $\lambda_{\max }$. $383 \mathrm{~m} \mu$ ]. With $n$-hexane as solvent, $K_{1}^{1} \%=1690$ at $\lambda_{\max }$. $370 \mathrm{~m} \mu$ was found [Hubbard et al. (1952-53) give $E_{1}^{1} \%=$ 1720 at $\lambda_{\max }, 369 \mathrm{~m} \mu$ in light petroleum]. In the CarrPrice test, $E_{1}^{1 \%} \mathrm{~cm}=3820$ at $\lambda_{\max } 664 \mathrm{~m} \mu$ was found [Robeson et al. (1955) give $E_{1}^{1} \%=3470$ at $\lambda_{\max .} 664 \mathrm{~m} \mu$ and Hubbard et al. (1952-53) $E_{1 \%}^{1 \%}=3970$, at $\left.\lambda_{\max .} 666 \mathrm{~m} \mu\right]$.
Reduction of vitamin $A_{1}$ aldehyde from herring eggs to the alcohol. The aldehyde was dissolved in a suitable volume of ethanol and the solution cleared by filtering through a no. 4 porosity sintered-glass funnel. A few milligrams of sodium borohydride were added and the absorption curve of the supernatant liquid was read after $20 \mathrm{~min}$. and showed a peak at $325 \mathrm{~m} \mu$.

Formation of anhydrovitamin $A_{1}$. To $1.5 \mathrm{ml}$. of the solution of vitamin $A_{1}$ alcohol, mentioned above, in a quartz spectrophotometer cell $1.5 \mathrm{ml}$. of a $0.04 \mathrm{~N}$-solution of hydrogen chloride in ethanol was added. The extinction at $390 \mathrm{~m} \mu$ was followed and when it ceased to rise (about 15 min. after mixing) the absorption curve of the solution was read and showed the typical three peaks of anhydrovitamin $A_{1}$ (Shantz, Cawley \& Embree, 1943).

Iodine isomerization. This was used to test for geometrical isomers in the vitamin $A_{1}$ aldehyde from herring eggs (Hubbard, 1956). The second method of Fisher, Kon $\&$ Plack (1957) was used.

Vaginal-smear assay. The method of Pugsley, Wills \& Crandall (1944) as modified by Clarke \& Todd (1957) was followed.

Chick liver-storage assay. A method based on that of Ames \& Harris (1956) but with smaller doses of vitamin A was used. Groups of deficient chicks were dosed daily for 5 days with vitamin $A_{1}$ acetate in arachis oil, given by dropper, or with herring eggs placed in the crop by means of a large syringe. Six days after the first dose, the chicks were killed and their livers removed and analysed for vitamin A. The method will be described in detail in a later paper.

Rat liver-storage test. Vitamin A-deficient rats were bred and fed as described by Thompson et al. (1949), but for a fortnight from the twenty-first day after birth they were given diet 172a (Clarke \& Todd, 1957), entirely devoid of vitamin $\mathrm{A}$ and carotenoids, to reduce more quickly their liver reserves. The deficient diet 213 (Henry, Kon, Mawson, Stanier \& Thompson, 1949) was then given again, supplemented with 35 i.u. of vitamin $\mathrm{D} /$ week, but vitamin $\mathrm{A}$ supplements were never given. When the rats were about 12 weeks old and their rate of growth had slowed down, the livers of representative animals of different weights were examined to ensure that vitamin A reserves were negligible (less than $1 \mu \mathrm{g}$./liver). Thereafter the rats either gained weight slowly or remained at the same weight for another 20 weeks, and were suitable for use during this period. Both male and female animals were used at different times in the work, and their weights were $200-350 \mathrm{~g}$. for males and 180-250 g. for females.

Before dosing, the rats were starved for $24 \mathrm{hr}$., receiving water only. The test material was offered on a palette dish. Untreated herring eggs, usually 15 g., were given with no additions; other solids were mixed with diet 213 and to liquid extracts enough diet 213 was added to absorb them, any solvents being removed in a stream of nitrogen. To reduce spilling, the diets were mixed to a paste with water. Paper was placed under each cage to catch any spillings, which were returned to the dish. In general, the test materials were eaten within $4 \mathrm{hr}$, , but occasionally it was necessary to add sucrose or diet to make them more palatable. When the dose had been eaten, diet 213 was offered $a d l i b$.

The rats were anaesthetized with diethyl ether $24 \mathrm{hr}$. after dosing, killed by bleeding from the heart and the 
livers removed, each being cut into small pieces and placed in a mixture of $30 \mathrm{ml}$. of ethanol and $15 \mathrm{ml}$. of water. Each liver was then extracted in a blender with two $100 \mathrm{ml}$. lots of light petroleum. The solvent was removed from the combined extracts and the residue saponified and chromatographed through ethanol-weakened B.D.H. Alumina. Vitamin $A_{1}$, all in the alcohol form, was eluted with $8 \%$ ethanol in $n$-hexane and estimated by the Carr-Price test. The results for the dosed rats were corrected by subtraction of the mean value for the control rats given diet 213 only.

The vitamin $A_{1}$ stored in the liver gave a rough estimate of the vitamin A activity of the dose, since storage usually amounted to about $25 \%$. When vitamin $A_{1}$ aldehyde was found to be the active substance, curves were prepared relating liver storage of vitamin $A_{1}$ to dose of vitamin $A_{1}$ aldehyde (see Figs. 3 and 4). Such curves showed that about $20 \mu \mathrm{g}$. of vitamin $A_{1}$ aldehyde had to be given before liver storage began. From these curves it was possible to calculate more accurately the vitamin A activity of the doses given in the earlier experiments.

\section{RESULTS}

\section{Herring eggs}

Dry-matter content. The dry-matter contents of the various batches of eggs were between 36.9 and $37 \cdot 4 \%$. Since they were uniform, results are given in terms of wet weight.

Comparison of biological assays of vitamin $A$ activity with chemical assays of vitamin $A_{1}$ ester and alcohol. Table 1 gives the results for chick liverstorage assays on two batches of eggs. The biologically determined activity was nine or ten times that due to the content of vitamin $A_{1}$ ester and alcohol. The carotenoids present were mainly xanthophylls and did not contribute significantly to the biological activity. Vitamin $A_{1}$ extracted from the livers of a group of chicks dosed with herring eggs behaved normally in the Carr-Price test and in $n$-hexane solution had an absorption maximum at $325 \mathrm{~m} \mu$.

A second biological assay on eggs of batch $\mathbf{A}$ showed that the vitamin A activity fell slightly on storage in deep-freeze for one year.
Association of the vitamin $A$ activity with protein. On several occasions, the residues and supernatant liquids from homogenates of eggs were tested for vitamin A activity by the rat vaginal-smear, chick liver-storage or rat liver-storage test. The supernatant liquid was always found active and the residue inactive, or very little active. Dialysis of a similar supernatant liquid against water did not remove the activity, which was precipitated by heating and by trichloroacetic acid.

Extraction of the vitamin $A$ activity into light petroleum. Curves $A$ and $B$ of Fig. 2 show the

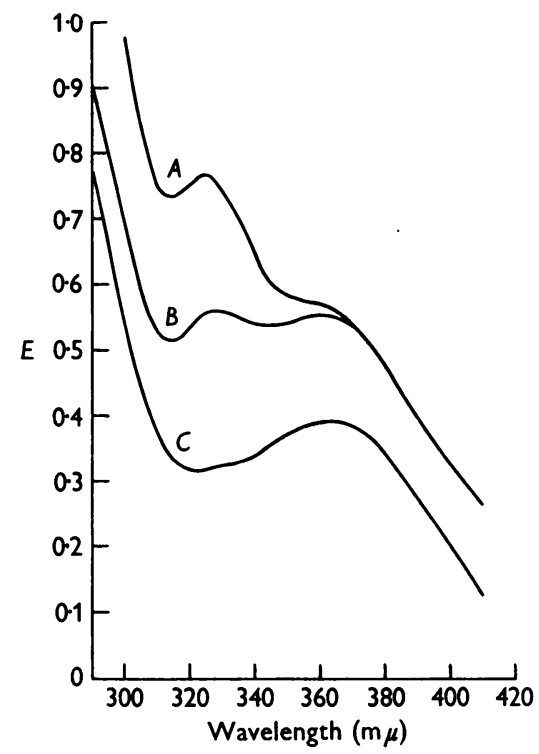

Fig. 2. Absorption curves of $(A)$ a $n$-hexane solution of a light-petroleum extract of herring eggs (batch D) containing extract from $0.5 \mathrm{~g}$. of eggs $/ \mathrm{ml}$., with a maximum at $325 \mathrm{~m} \mu$ and an inflexion at $360 \mathrm{~m} \mu$; $(B)$ a lightpetroleum extract of herring eggs (batch $\mathrm{E}$ ), $0.5 \mathrm{~g} . / \mathrm{ml}$., with maxima at 328 and $360 \mathrm{~m} \mu$; $(C)$ a light-petroleum solution of the vitamin $A_{1}$ aldehyde obtained from the extract of batch $E$ (curve $B$ ) by gradient elution from water-weakened P.S. Alumina, based on $0.5 \mathrm{~g}$. of eggs $/ \mathrm{ml}$., with a maximum at $365 \mathrm{~m} \mu$.

\section{Table 1. Comparison of biologically and chemically determined vitamin $A$ activity of herring eggs}

Biological activity was determined by the chick liver-storage test on blended eggs. Vitamin $A_{1}$ ester and alcohol were estimated by the Carr-Price test after extraction of the eggs with light petroleum in the presence of ethanol, saponification and chromatography.

Batch A

Batch $A$, stored in deep-freeze for 1 year

Batch B

\begin{tabular}{|c|c|}
\hline \multicolumn{2}{|c|}{ Chick liver-storage assay } \\
\hline $\begin{array}{l}\text { Vitamin } A_{1} \\
\text { equivalent } \\
(\mu \mathrm{g} \cdot / \mathrm{g} .)\end{array}$ & $\begin{array}{c}\text { True fiducial } \\
\text { limits at } \\
P=0.95\end{array}$ \\
\hline $5 \cdot 3$ & $4 \cdot 3-6 \cdot 3$ \\
\hline $4 \cdot 1$ & $3 \cdot 3-5 \cdot 0$ \\
\hline $4 \cdot 8$ & $4 \cdot 2-5 \cdot 3$ \\
\hline
\end{tabular}

* Mean of seven determinations on batch $\mathrm{C}$, the same raw material.

$\dagger$ Mean of four determinations on batch $\mathrm{C}$.
Chemical assay Vitamin $\mathbf{A}_{1}$ ester and

alcohol
( $\mu \mathrm{g} . / \mathrm{g}$.
$\mathbf{0 . 5 6}$
Xanthophylls ( $\mu \mathrm{g} \cdot / \mathrm{g} \cdot)$ $\mathbf{0 . 3 0}$

Carotenes ( $\mu \mathrm{g} \cdot \mathrm{g}$.)

$0 \cdot 46^{*}$ $1 \cdot 20 \dagger$ $0.05 t$ 
absorption of two light-petroleum extracts. Of these, curve $A$ is the more typical. The differences between them are discussed later. In Table 2, mean values are given for the storage of vitamin $\mathbf{A}_{1}$ by the rat from $15 \mathrm{~g}$. of eggs and from the lightpetroleum extract equivalent to $15 \mathrm{~g}$. of eggs. From the later results in Figs. 3 and 4, approximate values for the concentration of vitamin $\mathbf{A}_{1}$ aldehyde in the egge have been calculated, which show that about $70 \%$ of the activity was extracted into light petroleum.

Effect of acetone. The acetone-soluble and acetone-insoluble portions of a light-petroleum extract of batch $\mathbf{C}$ were given to rats in the liver-storage test. The acetone-soluble component was found to have very slight activity and the acetone-insoluble part no activity. Table 3 shows the results of a similar experiment in which the two fractions were tested separately and together. From the calculated values derived from Fig. 4 the activity after acetone treatment was about $40 \%$ of that of the original extract. In another experiment involving treatment with acetone for $1 \mathrm{hr}$. (Table 3), the recovery of the activity was $39 \%$.

Effect of saponification. Samples of lightpetroleum extract from batch $\mathbf{C}$ were saponified and the non-saponifiable residue was given to rats (Table 3). Calculation from Fig. 4 shows that about $60 \%$ of the original activity passed into the nonsaponifiable residue.

In chromatography of the non-saponifiable residue on ethanol-weakened B.D.H. Alumina, the original vitamin $A_{1}$ alcohol and ester (now in the alcohol form) were in the eluate with $8 \%$ ethanol in $n$-hexane. On several occasions the eluate with $2 \%$ acetone in $n$-hexane was tested by the CarrPrice reaction. A blue colour was produced with the absorption maximum and increase in intensity characteristic of vitamin $A_{1}$ aldehyde, although the pure substance does not survive saponification. On the assumption that the substance was the aldehyde a typical result for batch $D$ after this procedure was : vitamin $A_{1}$ aldehyde $1.52 \mu \mathrm{g} . / \mathrm{g}$. of eggs, vitamin $A_{1}$ ester plus alcohol $0.64 \mu \mathrm{g} . / \mathrm{g}$. of eggs.

Table 2. Comparison of the vitamin $A$ activities in the rat liver-storage test of herring eggs and of light-petroleum extracts from herring eggs

Samples of $15 \mathrm{~g}$. of eggs or the light-petroleum extracts from $15 \mathrm{~g}$. of eggs were given. Calculated concentrations of vitamin $A_{1}$ aldehyde in the eggs are derived from Figs. 3 and 4. M, male; F, female.

\begin{tabular}{|c|c|c|c|c|c|}
\hline & \multicolumn{2}{|c|}{ Rats } & \multirow{2}{*}{$\begin{array}{c}\text { Vitamin } A_{1} \\
\text { stored from } \\
15 \mathrm{~g} . \text { of eggs. } \\
\text { Mean value } \\
(\mu \mathrm{g} . / \text { liver })\end{array}$} & \multirow{2}{*}{$\begin{array}{l}\text { concn. of } \\
\text { vitamin } A_{1} \\
\text { aldehyde in } \\
\text { eggs }(a) \\
(\mu \mathrm{g} . / \mathrm{g} .)\end{array}$} & \multirow{2}{*}{$\begin{array}{c}\text { Percentage } \\
\text { extraction } \\
\text { calculated } \\
\text { from }(a)\end{array}$} \\
\hline & Sex & No. & & & \\
\hline Eggs, batch C & $\mathbf{M}$ & 7 & $25 \cdot 7$ & $6 \cdot 0$ & 一 \\
\hline $\begin{array}{l}\text { Light-petroleum extract } \\
\text { from eggs of batch } \mathrm{C}\end{array}$ & $\mathbf{M}$ & 18 & $15 \cdot 3$ & $4 \cdot 1$ & 68 \\
\hline Eggs, batch D & $\mathbf{F}$ & 9 & $30 \cdot 5$ & $6 \cdot 4$ & - \\
\hline $\begin{array}{l}\text { Light-petroleum extract } \\
\text { from eggs of batch D }\end{array}$ & $\mathbf{F}$ & 18 & $20 \cdot 1$ & $4 \cdot 7$ & 73 \\
\hline
\end{tabular}

Table 3. Liver storage of vitamin $A_{1}$ by male rats dosed with light-petroleum extracts of $15 \mathrm{~g}$. of herring eggs (batch $C$ ) or with extracts after various treatments

Calculated concentrations of vitamin $A_{1}$ aldehyde in the eggs are derived from Fig. 4.

Light-petroleum extract

Acetone-soluble part of extract

Acetone-insoluble part of extract

Acetone-soluble and acetone-insoluble parts of extract combined

Extract dispersed in acetone for $1 \mathrm{hr}$. at room temperature in the dark

Saponified extract
Vitamin $\mathbf{A}_{1}$ stored from $15 \mathrm{~g}$. of eggs. No. of rats

18

2

2

2

3

8

Calculated
concn. of
vitamin $A_{1}$
aldehyde in
eggs $(a)$
$(\mu \mathrm{g} \cdot / \mathrm{g} \cdot)$
$4 \cdot 1$
$1 \cdot 6$
0
$1 \cdot 7$
$1 \cdot 6$
2.4

Recovery calculated from (a)

(\%)

100

39

0

41

39

59 
Identification of vitamin $A_{1}$ aldehyde as the active constituent. The results from saponification experiments led us to attempt the separation of vitamin $A_{1}$ aldehyde from the original extract by chromatography. With ethanol-weakened B.D.H. Alumina, vitamin $A_{1}$ aldehyde is eluted with the esters by $2 \%$ acetone in $n$-hexane, but neither this fraction nor the eluates with $8 \%$ ethanol in hexane or with pure ethanol from the chromatography of a lightpetroleum extract of batch $\mathrm{C}$ gave rise to significant liver storage of vitamin $\mathrm{A}$ when given to rats. A light-petroleum extract of batch $D$ was chromatographed on water-weakened P.S. Alumina and Table 4 shows the results of giving the eluates to rats. Some vitamin A activity was present in the eluates with light petroleum and $5 \%$ diethyl ether in light petroleum, and calculations from Fig. 3 showed the combined recovery to be about $80 \%$. The absorption curve of a similar eluate with $5 \%$ diethyl ether in light petroleum was examined in $n$-hexane and gave an absorption maximum at $366 \mathrm{~m} \mu$, which again suggested the presence of vitamin $\mathbf{A}_{1}$ aldehyde.

Extracts were then examined by gradient elution from water-weakened P.S. Alumina. Fig. 1 shows a typical separation. The fractions containing vitamin $A_{1}$ aldehyde (nos. 10-26) were combined, taken to dryness and the residue was dissolved in light petroleum. In Fig. 2, curve $C$ is the absorption curve of the vitamin $A_{1}$ aldehyde in light petroleum $\left(\lambda_{\max } .365 \mathrm{~m} \mu\right)$. In ethanol, the absorption maximum was at $379 \mathrm{~m} \mu$. Reduction of this solution with sodium borohydride gave vitamin $A_{1}$ alcohol $\left(\lambda_{\max } 325 \mathrm{~m} \mu\right)$ and the identification of the product was confirmed by the formation of anhydrovitamin $A_{1}$.

From another separation, the fractions containing vitamin $A_{1}$ aldehyde gave the typical reaction of this compound in the Carr-Price test with a maximum absorption at $664 \mathrm{~m} \mu$. There was no peak at $735 \mathrm{~m} \mu$, so that vitamin $\mathrm{A}_{2}$ aldehyde was absent. Addition of a sample of all-trans vitamin $\mathbf{A}_{1}$ aldehyde to a light-petroleum extract of eggs before chromatography resulted in only one main peak in the fractionation curve.

Vitamin $A_{1}$ aldehyde separated from egg extracts by gradient elution behaved as the pure substance on ethanol-weakened heated B.D.H. Alumina and was eluted with $2 \%$ acetone in $n$-hexane. When the extract itself was chromatographed on this adsorbent, only a small amount of aldehyde, usually less than $25 \%$ of that obtained from waterweakened P.S. Alumina, was eluted by this solvent mixture. With unheated ethanol-weakened B.D.H. Alumina, $2 \%$ acetone in $n$-hexane eluted slightly more vitamin $\mathbf{A}_{1}$ aldehyde than from the heated adsorbent.

Isomerization of a sample of the vitamin $\mathbf{A}_{1}$ aldehyde with iodine resulted in no significant change in absorption maximum or in extinction.

Comparison of biological activities of extracts with chemically determined vitamin $A_{1}$ aldehyde, ester and alcohol. Light-petroleum extracts from $15 \mathrm{~g}$. of eggs (batch $D$ ) were given to rats, alone and with 60 and $120 \mu \mathrm{g}$. of added vitamin $A_{1}$ aldehyde, and another group of rats received vitamin $A_{1}$ aldehyde only. Fig. 3 shows the results with female rats. The difference in slope of the curves indicates that in the presence of the extract, liver storage from a given dose of vitamin $A_{1}$ aldehyde was rather better than when the aldehyde was fed alone. In Fig. 3, curve $C$ has therefore been drawn through the origin of curve $B$ (which a repeat experiment confirmed as $20 \mu \mathrm{g}$.) parallel to curve $A$, and this curve $C$ has been used for the conversion of $\mu \mathrm{g}$. of vitamin $A_{1} /$ liver into $\mu \mathrm{g}$. of vitamin $A_{1}$ aldehyde/ dose. In this experiment, the liver storage from an extract equivalent to $15 \mathrm{~g}$. of eggs was $20.8 \mu \mathrm{g}$. of vitamin $A_{1}$, which corresponds to a dose of $72 \mu \mathrm{g}$. of vitamin $A_{1}$ aldehyde or $4.8 \mu \mathrm{g} . / \mathrm{g}$. of eggs. The

Table 4. Liver storage of vitamin $A_{1}$ by female rats dosed with light-petroleum extracts of $15 \mathrm{~g}$. of herring eggs (batch $D$ ) or with fractions obtained by chromatography of an extract from $15 \mathrm{~g}$. of eggs on water-weakened P.S. Alumina

Calculated concentrations of vitamin $A_{1}$ aldehyde in the eggs are derived from Fig. 3.

\begin{tabular}{|c|c|c|c|}
\hline & $\begin{array}{l}\text { No. of } \\
\text { rats }\end{array}$ & $\begin{array}{c}\text { Vitamin } A_{1} \\
\text { stored from } \\
15 \mathrm{~g} . \text { of eggs. } \\
\text { Mean value } \\
(\mu \mathrm{g} . / \text { liver })\end{array}$ & $\begin{array}{c}\text { Calculated } \\
\text { concn. of } \\
\text { vitamin } A_{1} \\
\text { aldehyde in eggs } \\
(\mu \mathrm{g} . / \mathrm{g} .)\end{array}$ \\
\hline Light-petroleum extract & 18 & $20 \cdot 1$ & $4 \cdot 7$ \\
\hline Eluate with light petroleum & 2 & $1 \cdot 6$ & $1 \cdot 6$ \\
\hline $\begin{array}{l}\text { Eluate with } 5 \%(v / v) \text { diethyl } \\
\text { ether in light petroleum }\end{array}$ & 2 & $5 \cdot 5$ & $2 \cdot 2$ \\
\hline $\begin{array}{l}\text { Eluate with } 10 \%(v / v) \text { diethyl } \\
\text { ether in light petroleum }\end{array}$ & 2 & 0 & 0 \\
\hline Eluate with diethyl ether & 2 & 0 & 0 \\
\hline
\end{tabular}




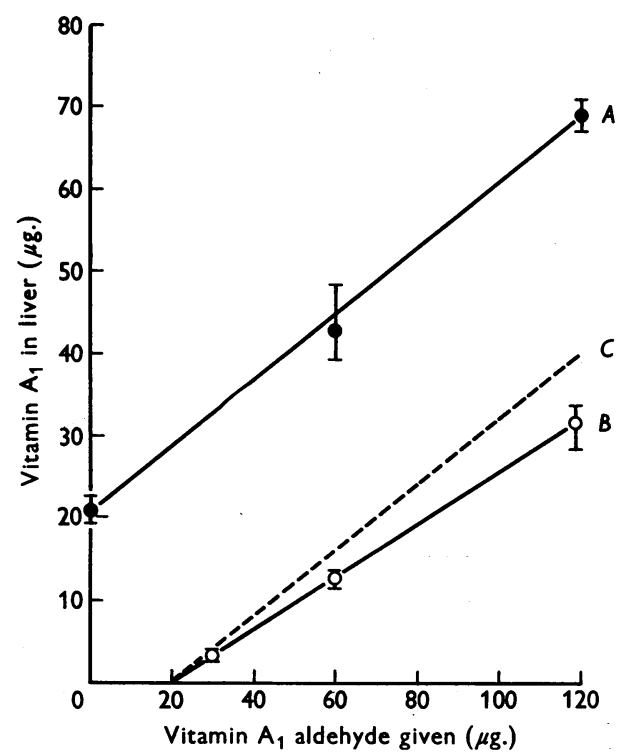

Fig. 3. Relationship between dose of vitamin $A_{1}$ aldehyde and vitamin $A_{1}$ stored in the liver of female rats. Each point is the mean value for three rats, except the first and last points of curve $A$, which are the means for two. Each vertical line represents the range of values, where these extend beyond the symbol. Curve $A$, lightpetroleum extract of $15 \mathrm{~g}$. of herring eggs (batch D), alone and with 60 and $120 \mu \mathrm{g}$. of added vitamin $A_{1}$ aldehyde. Curve $B$, vitamin $A_{1}$ aldehyde alone. Curve $C$, drawn through the origin of curve $B$ parallel to curve $A$ (see text).

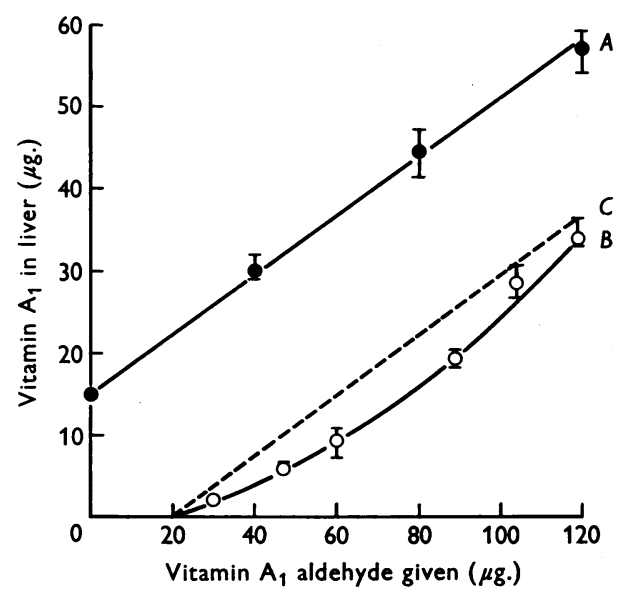

Fig. 4. Relationship between dose of vitamin $A_{1}$ aldehyde and vitamin $A_{1}$ stored in the liver of male rats. Each point is the mean value for four rats, and each vertical line represents the range of values where these extend beyond the symbol. Curve $A$, light-petroleum extract of $15 \mathrm{~g}$. of herring eggs (batch D), alone and with 40, 80 and $120 \mu \mathrm{g}$. of added vitamin $A_{1}$ aldehyde. Curve $B$, vitamin $A_{1}$ aldehyde alone. Curve $C$, drawn through the origin of curve $B$ parallel to curve $A$. vitamin $A_{1}$ aldehyde in this extract was estimated chemically, after separation by the gradientelution method, as $3.5 \mu \mathrm{g}$./g. of eggs. Vitamin $A_{1}$ ester and alcohol, determined together after saponification, amounted to $0 \cdot 8 \mu \mathrm{g}$./g. and since it was found that liver storage from vitamin $A_{1}$ acetate was essentially the same as from the aldehyde, the total chemical activity, equivalent to $4 \cdot 3 \mu$ g. of vitamin $A_{1}$ aldehyde/g., may be compared with the biological value of $4 \cdot 8 \mu \mathrm{g} \cdot / \mathrm{g}$.

Fig. 4 shows the result of a similar experiment with male rats, except that the light-petroleum extracts of eggs were given alone and with 40,80 and $120 \mu \mathrm{g}$. of added vitamin $A_{1}$ aldehyde. The values for vitamin $A_{1}$ aldehyde alone do not lie on a straight line. Curve $C$ has been drawn as in Fig. 3, and calculated values have been based on this curve. Liver storage from an extract equivalent to $15 \mathrm{~g}$. of eggs was $14 \cdot 9 \mu \mathrm{g}$. of vitamin $A_{1}$, corresponding to a dose of $61 \mu \mathrm{g}$. of vitamin $A_{1}$ aldehyde or $4 \cdot 1 \mu \mathrm{g}$./g. of eggs. Chemical determinations gave $3.6 \mu \mathrm{g}$. of vitamin $A_{1}$ aldehyde $/ \mathrm{g}$. and $0.8 \mu \mathrm{g}$. of vitamin $A_{1}$ ester and alcohol/g., equivalent to a total of $4 \cdot 4 \mu \mathrm{g}$. of aldehyde/g. of eggs.

Comparison of the properties of light-petroleum extracts with those of pure vitamin $A_{1}$ aldehyde. In Table 5 the properties of light-petroleum extracts of herring eggs are compared with those of pure vitamin $A_{1}$ aldehyde. The chromatographic behaviour on ethanol-weakened B.D.H. Alumina was markedly different, as were the effects of saponification and of acetone.

Extraction with other solvents. Solvent mixtures other than light petroleum and ethanol were tried in an attempt to extract more than the $70 \%$ of the biological activity obtained with the latter. Vitamin $A_{1}$ aldehyde in the extracts was determined chemically after separation by gradient elution from water-weakened P.S. Alumina. The results are compared in Table 6. Although mixtures of chloroform and methanol extracted more lipid soluble in $n$-hexane than did light petroleum with ethanol, there was no improvement in the amount of vitamin $\mathbf{A}_{\mathbf{1}}$ aldehyde extracted.

\section{Eggs of other teleost fishes}

The eggs of seven other species of teleost fishes were extracted with light petroleum in the presence of ethanol. Vitamin $A_{1}$ aldehyde was separated by gradient elution from water-weakened P.S. Alumina and estimated chemically; vitamin $A_{1}$ ester and alcohol were separated by chromatography on ethanol-weakened B.D.H. Alumina, saponified, chromatographed again on the same adsorbent and estimated by the Carr-Price test. Table 7 gives the vitamin $A_{1}$ aldehyde and ester plus alcohol concentrations, and the range of values obtained with 
Table 5. Comparison of the properties of pure vitamin $A_{1}$ aldehyde with those of a light-petroleum extract of herring eggs

Criterion

Carr-Price test

Chromatography on ethanolweakened heated B.D.H. Alumina

Chromatography by gradient elution from water-weakened P.S. Alumina

Saponification

Effect of acetone
Pure vitamin $A_{1}$ aldehyde Typical blue colour, doubling in intensity over $2 \mathrm{~min}$.

All present in $2 \%$ acetone in $n$-hexane eluate

Appears in fractions 10-26 when fractionated as in Fig. 1

Does not appear in non-saponifiable residue

No effect
Extract of herring eggs

Weak blue-grey colour produced, increasing slightly in intensity

Small amounts of aldehyde in $2 \%$ acetone in $n$-hexane eluate ('free' aldehyde)

Free aldehyde produced which appears in fractions $10-26$ (see Fig. 1)

Some free aldehyde in nonsaponifiable residue

Biological activity reduced to $40 \%$ of original

Table 6. Comparison of the amounts of lipid and vitamin $A_{1}$ aldehyde extracted from herring eggs by different methods

Extraction methods are described in the Experimental section. Vitamin $A_{1}$ aldehyde was estimated chemically after separation by gradient-elution from water-weakened P.S. Alumina.

\begin{tabular}{|c|c|c|}
\hline Method & $\begin{array}{l}\text { Lipid } \\
\text { (g./g. of eggs) }\end{array}$ & $\begin{array}{c}\text { Vitamin } A_{1} \\
\text { aldehyde } \\
\text { ( } \mu \text { g./g. of eggs) }\end{array}$ \\
\hline $\begin{array}{l}\mathrm{CHCl}_{3}-\text { methanol }(1: 1) \text { extract, } \\
n \text {-hexane-soluble part }\end{array}$ & $0.094^{*}$ & $4 \cdot 2^{*}$ \\
\hline $\begin{array}{l}\mathrm{CHCl}_{3}-\text { methanol }(2: 1) \text { extract, } \\
n \text {-hexane-soluble part }\end{array}$ & $0 \cdot 085^{*}$ & $4 \cdot 0^{*}$ \\
\hline Light-petroleum extract & $0.047 \dagger$ & $4 \cdot 2 \dagger$ \\
\hline Single estimations. & $\dagger$ Mean of five & timations. \\
\hline
\end{tabular}

Table 7. Concentrations of vitamin $A_{1}$ aldehyde and of vitamin $A_{1}$ ester and alcohol in the eggs of some marine teleost fishes

Estimations were done on light-petroleum extracts of the eggs. Vitamin $A_{1}$ aldehyde was separated by gradient elution from water-weakened P.S. Alumina. Vitamin $A_{1}$ ester and alcohol were separated on ethanol-weakened B.D.H. Alumina, saponified and purified by further chromatography. All estimations were by the Carr-Price test.

\begin{tabular}{lcc}
\multicolumn{1}{c}{ Fish } & $\begin{array}{c}\text { Vitamin } \\
\text { aldehyde } \\
(\mu \mathrm{g} . / \mathrm{g} .)\end{array}$ & $\begin{array}{c}\text { Vitamin } \mathbf{A}_{1} \\
\text { ester and } \\
\text { alcohol } \\
(\mu \mathrm{g} . / \mathrm{g} .)\end{array}$ \\
Cod (Gadus callarias L.) & $1 \cdot 3$ & $0 \cdot 1$ \\
Common dab [Limanda limanda (L.)] & $1 \cdot 6$ & $0 \cdot 1$ \\
Long rough dab [Hippoglossoides platessoides (Fabr.)] & $2 \cdot 8$ & $0 \cdot 1$ \\
Haddock (Gadus aeglefinus L.) & $2 \cdot 0$ & $0 \cdot 1$ \\
Turbot [Scophthalmus maximus (L.)] & $2 \cdot 3$ & $0 \cdot 2$ \\
Whiting (Gadus merlangus L.) & $2 \cdot 6$ & $0 \cdot 2$ \\
Witch [Glyptocephalus cynoglossus (L.)] & 1.5 & - \\
Herring (Clupea harengus L.) & $2 \cdot 4-5 \cdot 7$ & $0 \cdot 3-0.9$
\end{tabular}

herring eggs is given for comparison. The concentrations of aldehyde were all of the same order, and about ten times greater than the concentrations of ester plus alcohol.

\section{DISCUSSION}

In the early stages of this work (Fisher et al. 1956a) we were unable to extract the vitamin A activity of herring eggs into lipid solvents. The identification of the active substance as vitamin $A_{1}$ aldehyde explains why certain of the more drastic treatments with potassium hydroxide or hydrochloric acid were of no use. Nevertheless, our normal extraction with ethanol and light petroleum should have been effective then as it is now. In the earlier extracts, ethanol or ethanol-water mixtures were added to the eggs before the light petroleum, and we have observed that such treatment denatures the protein on the outside of the eggs to produce 
hard spheres not easily broken in the blender, which may explain our earlier lack of success. The present method avoids this difficulty by blending the eggs thoroughly alone and with light petroleum so that they are broken down before addition of the ethanol. Nevertheless it allows extraction of only about $70 \%$ of the vitamin $A$ activity detected biologically, and we have attempted to improve the extraction by varying the ethanol concentration and by using mixtures of chloroform and methanol. These modifications have not so far proved successful.

The carotenoids present in the extracts were mainly xanthophylls, with only small quantities of carotenes. Their contribution to the total vitamin A activity would be very small. In earlier experiments we had found that vitamin $A_{1}$ aldehyde was present at about the same concentration as the vitamin $\mathbf{A}_{1}$ ester and alcohol. The detection of what was apparently vitamin $\mathbf{A}_{1}$ aldehyde after saponification led us to examine the extracts more closely for this substance although, under our conditions, the pure aldehyde does not survive saponification. Water-weakened P.S. Alumina yielded more aldehyde from egg extracts than did ethanolweakened B.D.H. Alumina, and for quantitative work we have used gradient elution from waterweakened P.S. Alumina. This method has two advantages over stepwise elution. In the first place it is independent of small differences in different batches of adsorbent and in the second it is, within limits, independent of the quantity and quality of lipids present, which affect the elution of both vitamin $A_{1}$ ester and aldehyde.

From the results, the evidence for the identification of the active substance as vitamin $A_{1}$ aldehyde seems satisfactory, but the absorption maxima of $365 \mathrm{~m} \mu$ in light petroleum and $379 \mathrm{~m} \mu$ in ethanol are lower than the accepted values for all-trans vitamin $A_{1}$ aldehyde, $369 \mathrm{~m} \mu$ in light petroleum (Hubbard et al. 1952-53) and $383 \mathrm{~m} \mu$ (Hubbard et al. 1952-53) or $381 \mathrm{~m} \mu$ (Robeson et al. 1955) in ethanol. This displacement may be due in part to the irrelevant absorption present, and in part to the presence of isomers other than all-trans. The iodine-isomerization test indicates that the isolated aldehyde is probably an equilibrium mixture of isomers, in which the all-trans form is predominant.

Having established that vitamin $\mathbf{A}_{1}$ aldehyde was the major vitamin A-active substance present in herring eggs, we were able to derive curves relating liver storage of vitamin $A_{1}$ to dose of all-trans vitamin $A_{1}$ aldehyde in the rat liver-storage test. From these we found that the biological activities of light-petroleum extracts of the eggs were accounted for by their content of vitamin $A_{1}$ aldehyde, ester and alcohol. In these calculations we have assumed that vitamin $A_{1}$ ester and alcohol, expressed in terms of the alcohol, are biologically equivalent to the same weight of vitamin $\mathbf{A}_{1}$ aldehyde. This is not strictly true since there is a slight difference in molecular weight and, on a molar basis, Ames, Swanson \& Harris (1955) have found that all-trans vitamin $A_{1}$ aldehyde has $91 \%$ of the biological activity of all-trans vitamin $A_{1}$ acetate. The errors involved, however, are negligible. The agreement between biological assays of the extracts with all-trans vitamin $\mathbf{A}_{1}$ aldehyde as standard and the sums of the chemical activities indicates that isomers of the aldehyde with low biological activity can be present only in small amounts (Ames et al. 1955).

The identification of vitamin $\mathbf{A}_{1}$ aldehyde, however, is possible only after the extract has been chromatographed through water-weakened alumina. Table 5 shows that the properties of the crude extract are markedly different from those of pure vitamin $A_{1}$ aldehyde, particularly in the effects of saponification and of acetone. These properties suggest that in the original extract, most of the aldehyde groups are protected in some way, possibly by combination with another lipid or a non-lipid substance. This suggestion is supported by the absorption curves of two extracts given in Fig. 2. Curve $A$, with a peak at $325 \mathrm{~m} \mu$ and an inflexion at $360 \mathrm{~m} \mu$, was from batch $D$ of herring eggs, and the extract contained a total of $3.6 \mu \mathrm{g}$. of vitamin $A_{1}$ aldehyde/g. of eggs, of which $15 \%$ was free, that is eluted by $2 \%$ acetone in $n$-hexane from ethanol-weakened B.D.H. Alumina. Curve $B$, with two peaks at 328 and $360 \mathrm{~m} \mu$, was from a sample of batch $E$, and this particular extract contained a total of $2.9 \mu \mathrm{g}$. of vitamin $A_{1}$ aldehyde/ g. of eggs, of which $32 \%$ was free. The two curves are not directly comparable, since the absorption of extraneous substances and the concentration of total vitamin $A_{1}$ aldehyde were different, but the increase in free aldehyde seems to be related to less extinction in the $325 \mathrm{~m} \mu$ region and greater extinction in the $360 \mathrm{~m} \mu$ region. The quantities of vitamin $A_{1}$ ester and alcohol present would make only a small contribution to the $325 \mathrm{~m} \mu$ peak, corresponding to an extinction of about 0.070 for curve $A$, and less for curve $B$. It seems possible therefore that linkage of vitamin $A_{1}$ aldehyde through the aldehyde group, leaving only five conjugated double bonds as in vitamin $A_{1}$ ester and alcohol, causes the complex in eggs to exhibit additional absorption in the $325 \mathrm{~m} \mu$ region. The aldehyde may be present as a plasmalogen and we are investigating the nature of the complex and the liberation of free aldehyde. Assuming a molecular weight for the complex twice that of vitamin $A_{1}$ aldehyde, the active material comprises only $\frac{1}{5000}$ of the weight of the lipid present. 
The only function of vitamin A definable in chemical terms is in the visual cycle, and here it is also found as the aldehyde, combined with protein in the visual pigments. It is possible that in fish eggs also, the aldehyde form of vitamin $A_{1}$ is concerned in some fundamental biochemical reaction. We are at present investigating the different forms of vitamin $A$ in developing eggs of herring and salmon to find at what stage in development the aldehyde form disappears, or is no longer predominant.

To the best of our knowledge, our preliminary communication (Plack et al. 1957) was the first to report the occurrence of vitamin $A$ aldehyde in a tissue other than the eye. Since then, Scharpenseel \& Wolf (1958) have found small amounts of vitamin $\mathbf{A}_{1}$ aldehyde in the livers and adrenals of rats injected intraperitoneally with $1 \mathrm{mg}$. of tritium-labelled vitamin $A_{1}$ acetate. Table 7 shows that the aldehyde is present in the eggs of all eight marine teleost fishes we have so far examined, the concentration being some ten times greater than that of vitamin $A_{1}$ ester and alcohol, but with the same methods we did not detect it in hen's eggs, ox liver or cow's blood, ovaries or milk.

\section{SUMMARY}

1. The biological vitamin A activity of herring eggs is about ten times greater than the chemically determined content of vitamin $\mathbf{A}_{1}$ ester and alcohol.

2. Some $70 \%$ of the biological activity can be extracted with light petroleum in the presence of ethanol. The activity of these extracts is accounted for by $2 \cdot 4-5 \cdot 7 \mu \mathrm{g}$. of vitamin $A_{1}$ aldehyde/g. of eggs, with smaller quantities of vitamin $A_{1}$ ester and alcohol. Small quantities of carotenoids, mainly xanthophylls, are also present.

3. Most of the vitamin $A_{1}$ aldehyde is linked to some other substance in such a way that its characteristic properties are masked. Free aldehyde is liberated by chromatography through water-weakened alumina.

4. The eggs of all seven other species of marine teleost fishes examined contained vitamin $\mathbf{A}_{1}$ aldehyde at concentrations of $1-3 \mu \mathrm{g}$./g. The con- centration of the combined ester and alcohol forms was about ten times less.

We wish to thank Dr B. B. Rae for samples of fish eggs, Mr G. F. Harrison and Mrs P. E. E. Todd for carrying out biological assays and Mrs P. J. Plack for technical assistance.

\section{REFERENCES}

Ames, S. R. \& Harris, P. L. (1956). Analyt. Chem. $28,874$. Ames, S. R., Swanson, W. J. \& Harris, P. L. (1955). J. Amer. chem. Soc. 77, 4136.

Attenburrow, J., Cameron, A. F. B., Chapman, J. H., Evans, R. M., Hems, B. A., Jansen, A. B. A. \& Walker, T. (1952). J. chem. Soc. p. 1094.

Ball, S., Goodwin, T. W.\& Morton, R. A. (1948). Biochem. J. $42,516$.

Clarke, P. M. \& Todd, P. E. E. (1957). Brit.J.Nutr.11, 173.

Fisher, L. R., Harrison, G. F., Kon, S. K., Plack, P. A., Thompson, S. Y. \& Todd, P. E. E. (1956a). Proc. Nutr. Soc. 15, xi.

Fisher, L. R., Kon, S. K. \& Plack, P. A. (1957). Proc. Roy. Soc. B, 147, 200.

Fisher, L. R., Kon, S. K. \& Thompson, S. Y. (1952). J. Mar. biol. Ass. U.K. 31, 229.

Fisher, L. R., Kon, S. K. \& Thompson, S. Y. (1956b). J. Mar. biol. Ass. U.K. 35, 41.

Henry, K. M., Kon, S. K., Mawson, E. H., Stanier, J. E. \& Thompson, S. Y. (1949). Brit. J. Nutr. 3, 301.

Hubbard, R. (1956). J. Amer. chem. Soc. 78, 4662.

Hubbard, R., Gregerman, R. I. \& Wald, G. (1952-53). J. gen. Physiol. 36, 415.

Junker, M. (1952-53). Arch. FischWiss. 4, 19.

Junker, M. (1956). Arch. FischWiss. 7, 248.

Kon, S. K., McGillivray, W. A. \& Thompson, S. Y. (1955). Brit. J. Nutr. 9, 244.

Plack, P. A. (1956). Biochem. J. 64, 56.

Plack, P. A., Thompson, S. Y. \& Kon, S. K. (1957). Biochem. J. 68, 2 P.

Pugsley, L. I., Wills, G. \& Crandall, W. A. (1944). J. Nutr. 28, 365.

Robeson, C. D., Blum, W. P., Dieterle, J. M., Cawley, J. D. \& Baxter, J. G. (1955). J. Amer. chem. Soc. 77, 4120.

Scharpenseel, H. W. \& Wolf, G. (1958). Fed. Proc. 17, 491. Scheunert, A. \& Schieblich, M. (1934). Z. Untersuch. Lebensmitt. 68, 409.

Shantz, E. M., Cawley, J. D. \& Embree, N. D. (1943). J. Amer. chem. Soc. 65, 901.

Thompson, S. Y. (1949). Brit. J. Nutr. 3, 43.

Thompson, S. Y., Ganguly, J. \& Kon, S. K. (1949). Brit. J. Nutr. 3, 50. 